\title{
Assessment of Metal Toxicity in Marine Ecosystems: Comparative Toxicity Potentials for Nine Cationic Metals in Coastal Seawater
}

\author{
Dong, Yan; Rosenbaum, Ralph K.; Hauschild, Michael Zwicky
}

Published in:

Environmental Science \& Technology (Washington)

Link to article, DOI:

10.1021/acs.est.5b01625

Publication date:

2016

Document Version

Peer reviewed version

Link back to DTU Orbit

Citation (APA):

Dong, Y., Rosenbaum, R. K., \& Hauschild, M. Z. (2016). Assessment of Metal Toxicity in Marine Ecosystems: Comparative Toxicity Potentials for Nine Cationic Metals in Coastal Seawater. Environmental Science \& Technology (Washington), 50(1), 269-278. https://doi.org/10.1021/acs.est.5b01625

\section{General rights}

Copyright and moral rights for the publications made accessible in the public portal are retained by the authors and/or other copyright owners and it is a condition of accessing publications that users recognise and abide by the legal requirements associated with these rights.

- Users may download and print one copy of any publication from the public portal for the purpose of private study or research.

- You may not further distribute the material or use it for any profit-making activity or commercial gain

- You may freely distribute the URL identifying the publication in the public portal 
Dong Y, Rosenbaum RK, Hauschild MZ (2016) Assessment of metal toxicity in marine ecosystems - Comparative Toxicity Potentials for nine cationic metals in coastal seawater. Environ

$4 \quad$ Assessment of metal toxicity in marine ecosystems -

\section{Comparative Toxicity Potentials for nine cationic}

\section{metals in coastal seawater}

${ }^{\dagger}$ Division for Quantitative Sustainability Assessment, Department of Management Engineering, Technical University of Denmark, Nils Koppels Alle, Building 424, DK-2800 Kgs. Lyngby,

Denmark

${ }^{\ddagger}$ Irstea, UMR ITAP, ELSA-PACT - Industrial Chair for Environmental and Social Sustainability Assessment, 361 rue Jean-François Breton, BP 5095, F-34196 Montpellier Cedex 5, France

This study is a first attempt to develop globally applicable and spatially differentiated marine Comparative Toxicity Potentials (CTPs) or ecotoxicity characterization factors for metals in coastal seawater for use in Life Cycle Assessment. The toxicity potentials are based exclusively on marine ecotoxicity data and take account of metal speciation and bioavailability. CTPs were developed for nine cationic metals ( $\mathrm{Cd}, \mathrm{Cr}(\mathrm{III}), \mathrm{Co}, \mathrm{Cu}(\mathrm{II}), \mathrm{Fe}(\mathrm{III}), \mathrm{Mn}, \mathrm{Ni}, \mathrm{Pb}$ and $\mathrm{Zn}$ ) in 64 Large Marine 
19 Ecosystems (LMEs) covering all coastal waters in the world. The results showed that the CTP of a 20 specific metal varies 3-4 orders of magnitude across LMEs, largely due to different seawater

21 residence time. Therefore the highest toxicity potential for metals was found in the LMEs with the 22 longest seawater residence times. Across metals, the highest CTPs were observed for $\mathrm{Cd}, \mathrm{Pb}$ and $23 \mathrm{Zn}$. At the concentration levels occurring in coastal seawaters, Fe acts not as a toxic agent but an 24 essential nutrient and thus has CTPs of zero.

\section{Introduction}

Life Cycle Assessment (LCA) "quantifies all relevant emissions and resources consumed"1 associated with a good or service in a Life Cycle Inventory (LCI) and assesses "the related environment and health impacts and resource depletion issues"1 by Life Cycle Impact Assessment (LCIA). LCA has been broadly used to support environmentally informed decisions in policymaking, product development and procurement, and consumer choices ${ }^{2}$. It is a valuable screening

31 tool to facilitate identifying environmental hotspots ${ }^{2}$. The uncertainties associated with LCA results can be high due to data and simplified modelling ${ }^{2}$. This can be partially compensated by enhancing regional detailed modelling.

Metals are often ranked at the top of toxicity concerns in Life Cycle Assessment (LCA) ${ }^{3}$. Large quantities of metals are released from anthropogenic resources to the natural environment (up to $3 \times 10^{5}$ tons/year for selected metals, e.g. $\left.\mathrm{Mn}\right)^{4}$. Waterborne emissions contribute $50-80 \%$, and originate mainly in industrial sectors such as iron or steel production, thermal power stations, mineral oil and gas refineries etc. ${ }^{5}$ Waterborne metal emissions typically reach freshwater first and move towards seawater through fluvial pathways, thus potentially causing ecotoxicity in both freshwater and marine compartments ${ }^{6}$. Hitherto, metal toxicity in the aquatic environment has been modelled in LCIA using models developed to simulate the behaviour of organic chemicals with 
poor representation of the speciation behaviour of metals and bioavailability (e.g. USES-LCA $2.0^{7}$ used in ReCiPe, IMPACT $2002+^{8}$ ). Following the principles laid out in the Apeldoorn Declaration ${ }^{9}$ and the Clearwater Consensus ${ }^{10}$, Gandhi et al. ${ }^{11,12}$ developed a new method to calculate the toxicity potential of six metals in freshwater ecosystems (expressed as a Comparative Toxicity Potential (CTP), also known as a Characterization Factor in LCIA), including fate, bioavailability and effect of metals. Their CTP was calculated for a number of archetypical freshwater chemistries. Dong et al. ${ }^{13}$ further adapted the method, expanding its scope of metals and calculated freshwater CTP for 14 metals. The results showed that for some metals (e.g. Al, Be, $\mathrm{Cr}(\mathrm{III}), \mathrm{Cu}$ and $\mathrm{Fe}(\mathrm{III})$ ), freshwater CTP was highly dependent on the speciation of metal in a certain water chemistry, thus varying by 2-6 orders of magnitude in different water archetypes. This reveals the importance of 1) including metal speciation and bioavailability in the modelling and 2) identifying spatially determined and differentiated water chemistries.

In comparison, marine CTP of metals has received less attention. Following the Apeldoorn be set at zero for toxicity in the oceans." 9 In contrast, coastal seawater receives higher anthropogenic metal emissions not just through fluvial pathways ${ }^{6}$, but also from airborne emission and metals resuspended from the seabed ${ }^{14}$, leading to the observable metal concentrations in the exceeding the levels where metal becomes toxic to organisms.

Not all metal forms are toxic. Only bioavailable forms, often within the truly dissolved forms, can access a sensitive receptor, the biotic-ligand, and become hazardous ${ }^{16,17}$. In addition to metal availability, also its residence time in the coastal seawater is essential for the exposure and hence its CTP. For most metals, a substantial removal happens after entering coastal zone, where complex binding to Suspended Particulate Matter (SPM) followed by removal through sedimentation is 
increased $^{6}$. The fate of a metal in coastal seawater is thus strongly influenced by its tendency to adsorb to SPM, its solubility in seawater and its complexation affinity with particulate and dissolved organic matter ${ }^{18}$.

Until now metal marine CTP in the previous LCIA models has either not been calculated (e.g. USEtox $^{19}$, IMPACT $2002+^{8}$ ) or it has been derived neglecting speciation and bioavailability, and using freshwater toxicity data (e.g. USES-LCA ${ }^{7}$ ), with a questionable representativeness for saltwater organisms ${ }^{20}$. Moreover, as demonstrated by Gandhi and co-workers, metal freshwater CTP is highly sensitive to water chemistry ${ }^{21}$. While water chemistry parameters such as $\mathrm{pH}$, Dissolved Organic Carbon (DOC), SPM and salinity affect the speciation of metals, different seawater residence times (SRT) in different coastal zones also play a large role when determining the fate of metal in coastal compartment ${ }^{22,23}$. So far, no study has given a coherent treatment of the global spatial variability of metal marine CTP, considering speciation and applying toxicity data for marine organisms. As a consequence, toxic impacts on the marine ecosystem were either not at all considered in LCA studies or they were assessed with methods of limited reliability based on questionable assumptions. These shortcomings and the strives for a coherent consideration of marine biodiversity in LCA studies set the objectives of this study.

Aiming for consistency with the methodology developed for characterizing metal toxicity in freshwater $^{11,13}$ and applying marine ecotoxicity data availability in ECOTOX database ${ }^{24}$, the objective of this paper is to develop new, spatially differentiated and globally applicable marine CTPs for Cadmium (Cd), Cobalt (Co), Chromium(III) (Cr), Copper(II) (Cu), Iron(III) (Fe), Manganese(II) (Mn), Nickel (Ni), Lead $(\mathrm{Pb})$ and Zinc $(\mathrm{Zn})$, taking metal speciation and bioavailability into account, and investigating their variation over 64 Large Marine Ecosystems (LMEs) for emissions received in coastal seawater all over the world. 


\section{Methods}

\subsection{General framework}

For metals, $\mathrm{CTP}_{\mathrm{i}}$ for ecosystems is expressed as the Potentially Affected Fraction of species integrated over time and space $\left[(\mathrm{PAF}) \cdot \mathrm{day} \cdot \mathrm{m}^{3} / \mathrm{kg}_{\mathrm{emitted}}\right]$, representing the ecotoxicity potential for the total metal in compartment i. It is calculated as the product of three factors: Fate Factor (FF), Bioavailability Factor (BF) and Effect Factor (EF) as presented in Eq. $1^{11}$.

$$
C T P_{i}=F F_{i} \cdot B F_{i} \cdot E F_{i}
$$

Where:

$F F_{i}$ : $\quad$ Fate Factor [day], representing the residence time of total metal in compartment $i$,

$B F_{i}$ : Bioavailability Factor [dimensionless], representing the ratio between truly dissolved and total metal. Here truly dissolved metal contains metal free ion and inorganic metal complexes. Total metal includes truly dissolved metal, DOC complexed metal and SPM complexed metal.

$E F_{i}: \quad$ Effect Factor $\left[(\mathrm{PAF}) \cdot \mathrm{m}^{3} / \mathrm{kg}\right]$, representing the fraction of species potentially affected by the toxicity of the truly dissolved metal in compartment $i$.

This framework can be used for any single environmental compartment (e.g. freshwater, soil). When considering a multi-compartment system, the terms of eq. 1 become matrices, which besides residence times also include inter-compartmental transfers ${ }^{25}$. In this paper we focus on metals received from adjacent environmental compartments or directly emitted into the coastal seawater compartment. Therefore, FF represents the persistence of the metal in coastal seawater, while BF and EF represent bioavailability and metal ecotoxicity effects in coastal seawater respectively. FF is modelled for the total metal rather than dissolved metal, due to the fact that this is the entity which is reported in LCI and that the metal in the water may re-partition between particulate and dissolved forms during transportation. Note that the partitioning pattern can vary over time and with local 
113 environmental conditions. This can have an impact on the FF of metals. For the purpose of LCA 114 temporal variations need to be averaged over a year to be compatible to the information in the life 115 cycle inventory.

\subsection{Spatial differentiation of environmental conditions and parameters}

117 To explore the spatial variability of CTP in coastal seawater, we worked with the LMEs 118 following Cosme et al. ${ }^{26}$. The coastal compartment that is represented by a LME covers the marine 119 area from the coastal line to the seaward boundary of the continental shelf and includes any 120 estuaries. Thus defined, the coastal compartment with its adjacency to the continents receives 121 emissions related to human activity through the influx of continental freshwater or direct discharges 122 to the sea. $80 \%-90 \%$ of marine net primary production occurs in this compartment, which thus 123 comprises the majority of species and biomass that potentially may be affected by metal 124 emissions $^{27}$. The global coastal seawater zone was divided into 64 LMEs according to "distinct 125 bathymetry (seabed topography), hydrography, productivity and trophically dependent 126 populations" 28 , where each LME represents a relatively independent coastal zone. Data on SRT, 127 seawater surface area, temperature and water chemistry were collected for each LME from literature 128 (Table S1 in Supporting Information (SI)). The values for these parameters show large variations 129 across the 64 LMEs (Figure S1 in SI). SRT varies from 11 days-90 years, surface area from $1301.5 \times 10^{5}-5.7 \times 10^{6} \mathrm{~km}^{2}$, estuary discharge rate (water flow rate from freshwater to coastal seawater) 131 from $0-1.3 \times 10^{5} \mathrm{~m}^{3} / \mathrm{s}$, temperature from $-1{ }^{\circ} \mathrm{C}-29^{\circ} \mathrm{C}$, $\mathrm{pH}$ from $7.75-8.35$, DOC from 0.6-6.5 $\mathrm{mg} / 1$, 132 Particulate Organic Carbon (POC) from 31-802 ug/l, SPM from 0.2-2.9 mg/1 and salinity from 6.2$13340.3 \%$. For speciation modelling, salinity was translated into concentrations of the major ions $\left(\mathrm{Na}^{+}\right.$, $134 \mathrm{Mg}^{2+}, \mathrm{K}^{+}, \mathrm{Ca}^{2+}, \mathrm{SO}_{4}{ }^{2-}$, and $\mathrm{Cl}^{-}$) by scaling from a standard salinity (35\%) and its corresponding 135 major ion concentrations (Table S2 in SI), assuming a fixed relationship between the major ion 
concentrations at different salinities ${ }^{29}$. For each LME, the relevant environmental parameter and water chemistry values were applied to derive a CTP value for each metal.

138 Note that also within one LME, environmental parameters such as $\mathrm{pH}$, salinity, DOC, POC, and 139 SPM show both spatial and temporal variation. The annual variation ranges are shown for $\mathrm{pH}$, 140 salinity and POC within each LME in Figure S2 in SI. Fe, Mn and Al oxides have been shown to be 141 strong adsorbents for metal ions ${ }^{30-32}$, because of their large surface area. Due to lack of spatially 142 differentiated concentration data for these oxides, fixed concentrations of $0.15,0.02$ and $0.4 \mu \mathrm{g} / \mathrm{L}$ 143 for Fe, Mn, and Al oxides respectively had to be assumed across all $\mathrm{LMEs}^{33}$.

\subsection{Model and parameter selection}

\subsubsection{Fate model}

With the intended use in LCA in mind, the multimedia fate model embedded in USEtox ${ }^{19}$ was chosen for this study. USEtox is an LCIA model for assessing ecotoxicity and human toxicity impacts. It has been developed in a scientific consensus process involving LCIA and chemical fate modelling experts. It is the recommended characterization model for toxicity impacts in $\mathrm{LCA}^{34}$. In USEtox, the fate is calculated based on a steady-state mass balance. USEtox determines metal FF in the coastal seawater compartment by modelling of metal inflow, metal outflow and metal removal

152 (including sedimentation and sediment burial/re-suspension). Metal inflow and outflow largely depend on the retention time of the coastal seawater. Thus the default SRT of seawater on continental scale in USEtox was replaced by the SRT representative for each LME. To be consistent, also the default surface area of continental seawater and the water flow rate from continental freshwater to continental seawater (estuary discharge rate) were replaced by the corresponding LME-specific data. Water flow from ocean to coastal seawater is then automatically calculated from parameters mentioned above. Details of LME-specific data and calculations are available in Table S1 in SI. Metal removal is simulated by metal sedimentation and diffusion of 
metal from seawater to sediment. The former process is modelled by metal complexation with 161 SPM, followed by SPM sedimentation. The removal largely depends on the fraction of metal adsorbing to SPM, the concentration of SPM and the SPM sedimentation velocity. Metal diffusion into sediment is determined by the dissolved fraction of metal and the metal's mass transfer coefficient between sediment and water. The metal fraction adsorbed to SPM can be calculated from a spatially differentiated adsorption coefficient $\mathrm{Kp}_{\mathrm{SS}}(\mathrm{L} / \mathrm{kg}$; the ratio of metal concentration between SPM bound metal and truly dissolved metal). The truly dissolved fraction of metals is calculated using both $\mathrm{Kp}_{\mathrm{SS}}$ and $\mathrm{K}_{\mathrm{DOC}}(\mathrm{L} / \mathrm{kg}$; the ratio of metal concentration between DOC complex bound metal and truly dissolved metal). All parameters mentioned above vary between different LMEs. Thus $\mathrm{Kp}_{\mathrm{SS}}$ and $\mathrm{K}_{\mathrm{DOC}}$ were recalculated in WHAM VII ${ }^{35}$ for each metal in each LME respectively, to replace the default values in USEtox. WHAM ${ }^{35}$ is a metal speciation modelling software. Based on the input of target metal concentration and relevant water chemistry, it can deliver the concentration of target metal in a specific form. In WHAM's calculation of $\mathrm{Kp}_{\mathrm{SS}}$ and $\mathrm{K}_{\mathrm{DOC}}$ values, it is assumed that metals are in equilibrium with the discrete sites of DOC and the organic fraction of SPM. Here target metals have to compete with other cations (e.g. $\mathrm{Ca}^{2+}, \mathrm{Mg}^{2+}, \mathrm{K}^{+}$ and $\mathrm{Na}^{+}$) to form complexes with SPM or DOC. The ratio between the concentration of metal that is truly dissolved in water and the concentration of metal forming complexes with SPM or DOC were calculated for each LME and each metal as the specific $\mathrm{Kp}_{\mathrm{SS}}$ and $\mathrm{K}_{\mathrm{DOC}}$ value. Default DOC and SPM concentration in USEtox were also replaced by the corresponding specific parameter values

179 for each LME. Other landscape parameters were kept unchanged. All parameters used in FF 180 calculation are listed in Table S3 in SI. There were no substance parameter values for Mn and Fe in 181 default USEtox inorganic database. They thus had to be collected from literatures. The retrieved 182 values are presented together with substance parameter values for the other metals in Table S4 in 183 SI. 


\subsubsection{Bioavailability model}

$\mathrm{BF}, \mathrm{Kp}_{\mathrm{SS}}$, and $\mathrm{K}_{\mathrm{DOC}}$ all represent ratios between different metal species in coastal seawaters. They are thus dependent on the metal speciation in each LME. In the modelling of this speciation behaviour, we assumed that metals remained at their background concentration (Table S4 in SI) in coastal seawater before the emission. $\mathrm{BF}, \mathrm{Kp}_{\mathrm{SS}}$, and $\mathrm{K}_{\mathrm{DOC}}$ were then calculated for each LME with its specific water chemistry. This assumption is based on the fact that LCA assesses impacts caused by marginal changes. Nevertheless, a sensitivity analysis of the dependence of $\mathrm{BF}, \mathrm{K} \mathrm{p}_{\mathrm{SS}}$, and $\mathrm{K}_{\mathrm{DOC}}$ on background concentration change is performed in section 3.4.5.

WHAM VII ${ }^{35}$ was used to calculate metal speciation in seawater. While originally developed for freshwater, its applicability for prediction of metal free ion activity in seawater has been validated ${ }^{36}$. Furthermore it contains data and has a good reputation for simulating metal binding to DOC, POC, Fe oxide and Mn oxide. These two criteria favoured the choice of WHAM VII over other speciation models (e.g. Visual Minteq ${ }^{37}$, MINEQL $+{ }^{38}$, PHREEQC $^{39}$ ).

\subsubsection{Ecotoxicity model}

Currently there are two main ecotoxicity models to explain how cationic metals cause toxicity in organisms. The Free Ion Activity Model (FIAM) assumes that the toxic compound is free metal ion represented by its activity. The Biotic Ligand Model (BLM) further includes the competition between free metal ion and other cations (e.g. $\left.\mathrm{Ca}^{2+}, \mathrm{H}^{+}\right)$for binding to biotic ligand - the receptor in the target organism where the metal binds to exert its uptake and/or toxicity. Due to lack of BLMs for metals in seawater, FIAM was chosen in this study. It has been validated to assess metal toxicity to marine organisms in saltwater ${ }^{40,41}$. As stated in Clearwater Consensus ${ }^{10}$, we calculated EF based on truly dissolved metal, assuming that free ion is a fraction of truly dissolved metal and is responsible for the toxicity. In risk assessment, Predicted No Effect Concentration (PNEC) is typically used as effect indicator to protect the sensitive species of the ecosystem. Compared to 
208 PNEC, the geometric mean $\mathrm{HC}_{50}$ calculated from $\mathrm{EC}_{50}$, representing the Potentially Affected 209 Fraction (PAF) of species exposed above chronic $\mathrm{EC}_{50}$ values, is more robust but less 210 conservative $^{42}$. The purpose of LCA is to compare alternatives, where robustness is highly required. 211 Therefore $\mathrm{HC}_{50}$ values calculated from $\mathrm{EC}_{50}$ are normally applied in LCA. It can use all the 212 available toxicity data for a metal and is a measure associated with less uncertainty than the $213 \mathrm{PNEC}^{43,44}$. Detailed descriptions of calculation methods for the PAF method and $\mathrm{HC}_{50}$ can be found 214 in Larsen et al. ${ }^{44,45}$. EFs were calculated exclusively from data on chronic marine $\mathrm{EC}_{50}$ from 215 literature. The availability of marine ecotoxicity data in the ECOTOX database ${ }^{24}$ allowed us to 216 apply our model to nine cationic metals, including $\mathrm{Cd}, \mathrm{Co}, \mathrm{Cr}, \mathrm{Cu}, \mathrm{Fe}(\mathrm{III}), \mathrm{Mn}, \mathrm{Ni}, \mathrm{Pb}$, and $\mathrm{Zn}$ 217 (Table S5 in SI). For metals where chronic marine ecotoxicity data were insufficient, extrapolation 218 from acute marine ecotoxicity data was performed applying an Acute-to-Chronic Ratio (ACR) 219 derived from the available toxicity data as described in Table S6 in SI. Total metal marine $\mathrm{EC}_{50}$ 220 reported in literature were translated into free ion $\mathrm{EC}_{50}$ using WHAM VII ${ }^{35}$, taking into account 221 water chemistry of the test medium in which the reported $\mathrm{EC}_{50}$ was determined. This conversion 222 reduced the standard deviation of the $\mathrm{EC}_{50}$ of each metal by at least an order of magnitude (Table 223 S5), which also justifies the use of FIAM in EF calculation.

224 The calculation of EF was based on the recommended principles for $\mathrm{LCA}^{43,45,46}$. For each metal at 225 each trophic level (i.e. primary producers, primary and secondary consumers), a free ion activity $226 \mathrm{HC}_{50-\text { trophic }}$ was calculated as the geometric mean of the corresponding free ion $\mathrm{EC}_{50}$ for all species 227 with available data. The geometric mean of the resulting three $\mathrm{HC}_{50 \text {-trophic }}$ represents the free ion 228 activity $\mathrm{HC}_{50}$ in saltwater for that specific metal. Then, for each combination of metal and LME, a 229 truly dissolved $\mathrm{HC}_{50}$ was calculated using WHAM VII, based on the free ion activity $\mathrm{HC}_{50}$ and corresponding LME water chemistry. Finally, EF was calculated as $0.5 /$ truly dissolved $\mathrm{HC}_{50}{ }^{43}$. 


\section{Results and Discussion}

232 In this section the results for the spatially differentiated FF, BF, EF and CTP are discussed. The 233 results are shown for all combinations of metals and LMEs in Table S7 in SI.

\subsection{Fate Factors}

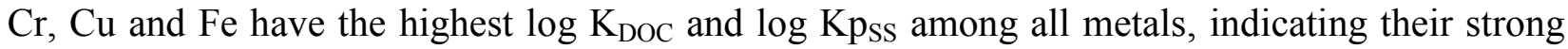
tendency of complexation with Organic Matter (OM, represented by DOC and the organic fraction of SPM (POC)) in seawater (Figure S3 in SI). This is in accordance with previous findings that $\mathrm{Cr}$,

$238 \mathrm{Cu}$ and $\mathrm{Fe}$ have high affinity for $\mathrm{OM}^{47}$. Compared with empirical values, $\mathrm{Kp}_{\mathrm{SS}}$ in this study were 239 generally within an order of magnitude (Table 1).

240 Both $\log \mathrm{K}_{\mathrm{DOC}}$ and $\log \mathrm{K}$ ss vary linearly with $\mathrm{OM}$ concentrations and salinity $\left(0.31<\mathrm{R}^{2}<0.93\right.$, $241 \mathrm{p}<0.001$, Table S8) for all metals except $\mathrm{Pb}$ and Fe. OM in WHAM is considered as humic 242 molecules, which are "rigid spheres, with proton-dissociating groups at the surface that can bind 243 metal ions." 48 Metal ion binding to a humic molecule can be simply expressed by the general 244 reaction in Eq.2, which is described by the intrinsic association constant $\mathrm{K}_{\mathrm{M}}(\mathrm{Eq} .3)^{48}$.

$$
R^{Z}+M^{Z}=R M^{Z+Z}
$$

$$
K_{M}=\frac{\left[R M^{Z+z}\right]}{\left[R^{Z}\right]\left[M^{z}\right]}
$$

Here $\mathrm{R}$ is the humic molecule, $\mathrm{M}$ is metal and $\mathrm{z}$ is the net charge. Under similar conditions (e.g. $248 \mathrm{pH}$ value, temperature, etc.), $\mathrm{K}_{\mathrm{M}}$ stays within a comparably narrow range. Therefore increasing $\mathrm{OM}$ 249 concentration leads to a higher concentration of metal-OM complex, resulting in a higher $\log \mathrm{K}_{\mathrm{DOC}}$ 250 and $\log \mathrm{Kp}_{\mathrm{SS}}$. When salinity increases, the metal ions are in stronger competition with major cations 251 in the seawater for the binding sites on OM, thus decreasing $\log \mathrm{K}_{\mathrm{DOC}}$ and $\log \mathrm{Kp}_{\mathrm{SS}}{ }^{49}$. The exception 252 for $\mathrm{Pb}$ and $\mathrm{Fe}$ is due to the fact that the binding of $\mathrm{Pb}$ and $\mathrm{Fe}$ to $\mathrm{DOC}$ and particles is not only 
253 influenced by $\mathrm{OM}$ concentrations and salinity, but also by other parameters (e.g. temperature and $254 \mathrm{pH}$ values).

255 Table 1: $\log _{\mathrm{K}} \mathrm{pss-D}^{\mathrm{a}}$ values $(\mathrm{L} / \mathrm{kg})$ in this study compared with empirical $\log \mathrm{Kp}$ ss-D $^{\mathrm{b}}$ values $(\mathrm{L} / \mathrm{kg})$ 256 developed in other studies.

\begin{tabular}{|c|c|c|}
\hline Metals & $\begin{array}{c}\log K p_{\text {SS-D }} \text { in this study } \\
(\text { mean } \pm \text { standard deviation) }\end{array}$ & $\log K p_{\text {SS-D }}$ in other studies \\
\hline $\mathbf{C d}$ & $2.9 \pm 0.3$ & $\begin{array}{l}4.0^{50} ; \\
4.3^{51} ; \\
3.5-5.5^{52}\end{array}$ \\
\hline Co & $2.7 \pm 0.2$ & $\begin{array}{l}4.6^{51} ; \\
4.5-6.0^{52}\end{array}$ \\
\hline $\mathrm{Cr}$ & $5.5 \pm 0.2$ & $\begin{array}{l}5.5^{50} \\
5.0-7.0^{52}\end{array}$ \\
\hline $\mathbf{C u}$ & $5.5 \pm 0.2$ & $\begin{array}{l}4.3^{53} \\
4.9^{50} \\
5.0^{54} ; \\
3.5-5.5^{52}\end{array}$ \\
\hline $\mathrm{Fe}$ & $5.5 \pm 0.2$ & $5.0-7.5^{52}$ \\
\hline Mn & $3.5 \pm 0.2$ & $\begin{array}{l}3.5^{51} \\
3.0-6.0^{52}\end{array}$ \\
\hline $\mathbf{N i}$ & $3.8 \pm 0.2$ & $\begin{array}{l}4.4^{50} \\
2.5-5.0^{52}\end{array}$ \\
\hline $\mathbf{P b}$ & $4.8 \pm 0.2$ & $\begin{array}{l}5.5^{50} \\
6.0^{53} ; \\
6.0^{54} ; \\
4.0-6.5^{52}\end{array}$ \\
\hline Zn & $4.2 \pm 0.2$ & $\begin{array}{l}3.0^{51} ; \\
4.5^{50} ; \\
5.2^{53} ; \\
5.5^{54} ; \\
4.0-6.0^{52}\end{array}$ \\
\hline
\end{tabular}

a. $\log \mathrm{Kp}_{\mathrm{SS}}(\mathrm{L} / \mathrm{kg})$ in this study represents the calculated partitioning coefficient between metal bound to SPM and truly dissolved metal. Log Kpss-D $(\mathrm{L} / \mathrm{kg})$ in other studies represents the partitioning coefficient between metal bound to SPM and total dissolved metal. To make the values comparable, we calculated $\log \mathrm{Kp} \mathrm{pSS}_{\mathrm{S}-\mathrm{D}}$ values from the $\log \mathrm{Kp}_{\mathrm{SS}}$ that we determined in this study. 
b. Log Kp $\mathrm{pSS}_{\mathrm{D}}$ values in literature were presented as a function of other water chemistry parameters (e.g. salinity and SPM). Here we took approximate values derived from water chemistry similar to this study (e.g. SPM $\approx 1 \mathrm{mg} / \mathrm{L}$, Salinity $\approx 30 \%$-35\%o, etc.)

FF is largely influenced by $\log \mathrm{Kp}_{\mathrm{SS}}$ and $\log \mathrm{K}_{\mathrm{DOC}}$. Metals with high $\log \mathrm{K} \mathrm{p}_{\mathrm{SS}}$ and $\log \mathrm{K}_{\mathrm{DOC}}(\mathrm{e} . \mathrm{g}$. $266 \mathrm{Cr}, \mathrm{Cu}$ and $\mathrm{Fe}$ ) have an efficient removal, due to complex formation with $\mathrm{OM}$ followed by 267 sedimentation. Therefore they have the lowest FF in all LMEs (Figure 1a). In contrast, FFs of Cd 268 and Co are the highest across all metals, due to their low $\log \mathrm{Kp}_{\mathrm{SS}}$ and $\log \mathrm{K}_{\mathrm{DOC}}$. For a given metal, 269 FF increases with SRT across LMEs (Figure S4 in SI). For Cd, Co, Mn, Ni, Pb and Zn, FF and SRT 270 are linearly correlated with $\mathrm{SRT}\left(\mathrm{R}^{2}>0.97, \mathrm{p}<0.001\right.$, Table $\mathrm{S} 8$ in SI). It means that FF variation 271 mainly depends on SRT and metal removal processes play a minor role. For the metals with high $272 \log \mathrm{Kp}_{\mathrm{SS}}$ and $\log \mathrm{K}_{\mathrm{DOC}}(\mathrm{e} . \mathrm{g} . \mathrm{Cr}, \mathrm{Cu}$ and $\mathrm{Fe}$ ), metal removal processes show a stronger influence on 273 FF. Thus FFs for these three metals are less strongly correlated to SRT, but rather determined by the 274 variation of $\mathrm{SRT}, \log \mathrm{Kp}_{\mathrm{SS}}$, and $\log \mathrm{K}_{\mathrm{DOC}}$ together. Note that the metals with lower $\mathrm{Kp}$ SS and $\log$ $275 \mathrm{~K}_{\mathrm{DOC}}(\mathrm{Cd}, \mathrm{Co}, \mathrm{Mn}, \mathrm{Ni}$ and $\mathrm{Zn})$ can have a FF that is higher than SRT in some LMEs. The reason is 276 that for these combinations of metal and ecosystem, the removed fraction is insignificant compared 277 to the total input. A non-negligible fraction of the metal flows out to the ocean, from where some of 278 it eventually recirculates back to the coastal seawater system after reaching steady state that USEtox 279 calculates. This results in a longer FF than the water that originally carried them out. The effect is 280 most pronounced in the LMEs with short SRTs because the inflow from the ocean is more 281 important compared to the volume and the freshwater input for these LMEs. 

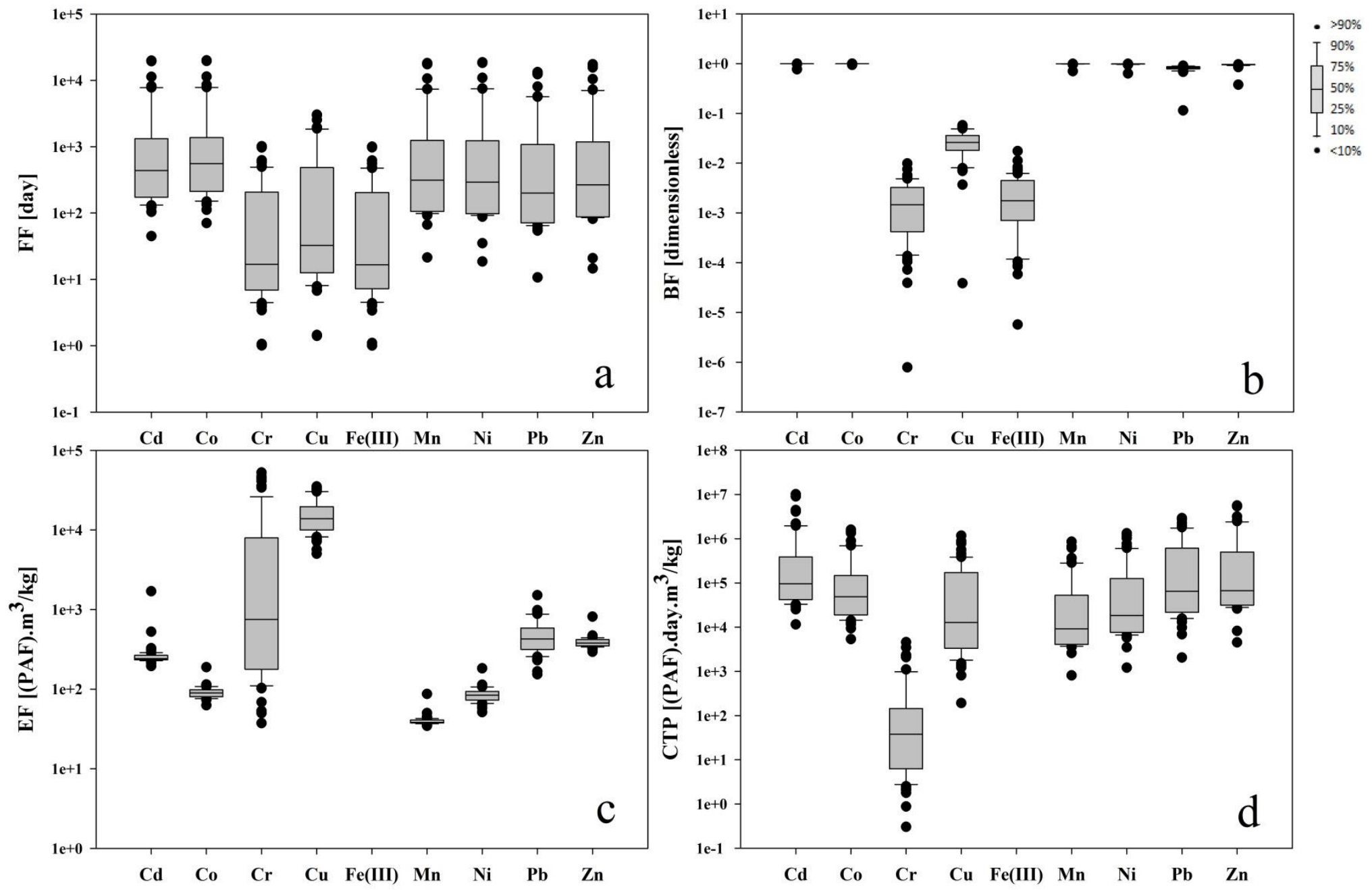

283 Figure 1. Variation of Fate Factor (FF, 1a), Bioavailability Factor (BF, 1b), Effect Factor (EF, 1c) and Comparative Toxicity Potential

284 (CTP, 1d) for nine metals determined across the 64 LMEs in this study. 
FF varies 2-3 orders of magnitude across LMEs for each metal. Within one LME, FF variation between different metals is within two orders of magnitude (Figure S5a in SI). It indicates that FF is slightly more sensitive to environmental parameters than to properties of metal.

We compared our FF with data from other studies. The age of water constituent models the residence time of seawater constituents in particle forms in seawater by simulating particle cycling ${ }^{55}$ and is similar to the concept of FF in this study. The constituent age of Baltic Seawater varies between a few days and up to 40 years ${ }^{56}$, which is similar to the range of metal FF in the Baltic Sea (LME 23) in this study (3-21years). The constituent age of Kara Seawater is 1-2 years ${ }^{57}$, which is within the range of the metal FF in the Kara Sea (LME 58) in this study (1-4 years). The constituent age of Norwegian Seawater and North Seawater combined together is $5-8$ years ${ }^{58}$, which is slightly larger than the sum of metal FF ranges in the Norwegian Sea (LME 21) and the North Sea (LME $22)$ in this study ( $1-5$ years).

\subsection{Bioavailability Factors}

Representing the fraction of total metal in coastal water that is truly dissolved, $\mathrm{BF}$ of $\mathrm{Cd}, \mathrm{Co}, \mathrm{Mn}$, $299 \mathrm{Ni}, \mathrm{Pb}$ and $\mathrm{Zn}$ varies less than a factor of eight across LMEs (Figure 1b). For $\mathrm{Cr}, \mathrm{Cu}$ and $\mathrm{Fe}$ the 300 variations in $\mathrm{BF}$ are much larger with 3-4 orders of magnitude, due to their large variations in log $301 \mathrm{~K}_{\mathrm{DOC}}$ and $\log \mathrm{K} \mathrm{p}_{\mathrm{SS}}$ across LMEs (Figure $1 \mathrm{~b}$ ). For all metals, clear correlations were observed 302 between $\mathrm{BF}$ and $\log \mathrm{K}_{\mathrm{DOC}}$ or $\log \mathrm{K}_{\mathrm{sS}}$ (Figure $\mathrm{S} 6$ ). This implies that BF is largely determined by 303 metal binding to DOC $\left(\log \mathrm{K}_{\mathrm{DOC}}\right)$ and SPM $\left(\log \mathrm{Kp} \mathrm{ps}_{\mathrm{SS}}\right)$. Co has the highest BF in all LMEs across 304 metals, due to its low $\log \mathrm{K}_{\mathrm{DOC}}$ and $\log \mathrm{Kp}$ ss. Similarly, $\mathrm{Cr}, \mathrm{Cu}$ and $\mathrm{Fe}$ have the lowest $\mathrm{BF}$ across all 305 LMEs, due to their high $\log \mathrm{K}_{\mathrm{DOC}}$ and $\log \mathrm{K} \mathrm{p}_{\mathrm{SS}}$ values (Figure $1 \mathrm{~b}$ and Figure $\mathrm{S} 6$ in $\mathrm{SI}$ ). 


\subsection{Effect Factors}

307 Some nutrient metals are essential for biota growth (e.g. $\mathrm{Co}, \mathrm{Cu}, \mathrm{Fe}, \mathrm{Mn}, \mathrm{Ni}$ and $\mathrm{Zn}$ ) ${ }^{59,60}$. 308 However, some of them may not reach the essential concentration to support biota growth under 309 normal conditions in seawater, due to their low concentrations (at nmol level, Table S4 in SI). 310 Under such circumstances, instead of being a toxic pollutant, a metal emission is more likely to 311 facilitate biota growth. It is meaningless to talk about contribution to ecotoxicity under these 312 circumstances. Therefore a true zero value of coastal CTP is given for those metals, in agreement 313 with the recommendation in the Apeldoorn declaration ${ }^{7}$. For the metals covered in this study the 314 essentiality condition appears to be relevant only for Fe, where the essential concentration range lies 315 above its background concentration in coastal waters. This is caused by efficient removal of Fe in 316 the estuary (ca. 90\%) via precipitation, flocculation, and sedimentation ${ }^{6}$. Meanwhile, fluvial 317 pathways contribute $75 \%$ of $\mathrm{Fe}$ inputs to seawater ${ }^{18}$, which leads to a low concentration of 318 dissolved Fe in seawater. Morel et al. ${ }^{59}$ reviewed the essential concentration of metals in seawater 319 and found that for the metals $\mathrm{Co}, \mathrm{Cu}, \mathrm{Mn}, \mathrm{Ni}$ and $\mathrm{Zn}$, the background concentration in seawater is 320 sufficient to support biota growth. This is in accordance with other studies showing that iron is the 321 only limiting nutrient metal for algae growth in seawater ${ }^{61-63}$. Therefore, a true zero was given to 322 the EF of Fe in all LMEs, which were excluded from the discussions in the rest of this section.

EFs show a modest variation, staying within one order of magnitude difference across all LMEs except for $\mathrm{Cr}$, which shows a larger variation of three orders of magnitude (Figure 1c). Cu has the highest EFs in 90\% of the LMEs, while Mn has the lowest EFs in all LMEs.

$\mathrm{EF}$ is influenced by temperature, $\mathrm{pH}$, salinity and $\mathrm{OM}$ through their impacts on the speciation (the 327 fraction of free ion activity within truly dissolved metal). In general, with increasing $\mathrm{pH}$, the metal may form hydroxide or carbonate complexes, decreasing the metal free ion concentration in solution, which leads to a lower $\mathrm{EF}^{64}$. Increases in salinity leads to a higher ionic strength, which 
330 results in lower free ion activity for a given free ion concentration, and thus a lower $\mathrm{EF}^{65}$. When 331 OM decreases, a fraction of metal may be released into truly dissolved forms, which leads to a 332 higher truly dissolved $\mathrm{HC}_{50}$, thus lower EF.

\subsection{Comparative Toxicity Potentials}

334 The comparative toxicity potentials are calculated as the product of FF, BF and EF following 335 Eq.1. Results are shown in Figure 1d. Due to its background concentration below essentiality levels 336 in coastal seawater ecosystems, the effect factor of Fe was set to zero and as a consequence its CTP 337 also becomes zero.

\subsubsection{Spatial variability of Comparative Toxicity Potentials}

$339 \mathrm{Cr}$ and $\mathrm{Cu}$ show the largest variation in CTP across LMEs with four orders of magnitude (Figure 340 1d). For $\mathrm{Cr}$ the variation is mainly driven by the variation in $\mathrm{EF}\left(\mathrm{R}^{2}=0.60, \mathrm{p}<0.001\right.$, Figure $\mathrm{S} 7$ in $341 \mathrm{SI})$, and less influenced by variation of $\mathrm{FF}$ and $\mathrm{BF}\left(\mathrm{R}^{2}<0.15\right)$. For $\mathrm{Cu}$ no single individual parameter 342 shows a significant correlation with CTP.

343 CTPs of $\mathrm{Cd}, \mathrm{Co}, \mathrm{Mn}, \mathrm{Ni}, \mathrm{Pb}$ and $\mathrm{Zn}$ vary by three orders of magnitude across LMEs (Figure 1d). 344 These metals have rather stable BF and EF, which vary less than one order of magnitude across 345 LMEs. Thus CTP variations are largely caused by FF. As FF of these metals is linearly correlated 346 with SRT, CTP is overall strongly driven by the variation in SRT $\left(0.64<\mathrm{R}^{2}<0.96\right.$, Figure S8b in SI), 347 with higher CTP for longer SRT.

\subsubsection{Ranking of Comparative Toxicity Potentials}

349 Among all metals, Cd has the highest CTP in 45\% of the LMEs (Figure S5d in SI), followed by $350 \mathrm{Zn}(31 \%)$ and $\mathrm{Pb}(24 \%)$. These three metals have high FF, BF and middle to high EF. They are 351 ranked among the top four CTPs in all LMEs. In contrast, $\mathrm{Cr}$ has the lowest CTP in all LMEs (apart 352 from $\mathrm{Fe}$, for which $\mathrm{CTP}$ is zero). Although its $\mathrm{EF}$ is in the middle range compared to the other 
metals, its BF and FF are constantly low in all LMEs, due to its high $\log \mathrm{K}_{\mathrm{DOC}}$ and $\log \mathrm{Kp}$ Ss. Also

$354 \mathrm{Mn}$ and Ni are consistently in the lower ranking of CTP in all LMEs $\left(5^{\text {th }}-7^{\text {th }}\right)$, due to their low EFs.

355 For $\mathrm{Cd}, \mathrm{Co}, \mathrm{Mn}, \mathrm{Ni}, \mathrm{Pb}$ and $\mathrm{Zn}$, variation in CTP is significantly driven by SRT. Thus, the highest 356 CTPs for these metals are observed in LME 5 (Gulf of Mexico), LME 26 (Mediterranean), and 357 LME 62 (Black Sea), which have the longest residence time across LMEs (90 years). In contrast, 358 the lowest CTP is observed in LME 35 (Golf of Thailand), which has the $2^{\text {nd }}$ shortest SRT among 359 all LMEs (15 days).

360 CTPs ranking for $\mathrm{Cr}$ and $\mathrm{Cu}$ across LMEs are largely determined by SRT and by temperature 361 through its influence on speciation. The highest CTPs are found in LME 64 (Antarctic), where the $3622^{\text {nd }}$ lowest temperature $\left(-1.20^{\circ} \mathrm{C}\right)$ and long SRT (11 years) are observed. In contrast, they have the 363 lowest CTP value in LME 35 (Golf of Thailand), which has the $2^{\text {nd }}$ highest temperature and $2^{\text {nd }}$ 364 shortest SRT.

\subsubsection{Comparison between freshwater and coastal CTPs}

$\mathrm{Cd}, \mathrm{Co}, \mathrm{Cr}, \mathrm{Mn}, \mathrm{Ni}$ and $\mathrm{Zn}$ marine CTPs show similar ranges to freshwater CTP determined by 367 Dong et al. ${ }^{13}$ using a parallel approach (Figure 1d). These similarities hide remarkable differences in 368 fate and effect behaviour in freshwater and coastal waters, which tend to neutralize each other in the 369 calculation of the CTPs. For these metals, EFs are thus up to two orders of magnitude lower in 370 seawater due to higher free ion activity $\mathrm{HC}_{50}$ in seawater (Table $\mathrm{S} 9$ in $\mathrm{SI}$ ). This is in accordance 371 with previous research that freshwater species are more sensitive to metals than marine species ${ }^{66}$. In 372 contrast, FFs are up to two orders of magnitude higher in seawater due to longer water residence 373 times in many LMEs (the residence time of freshwater is 143 days at maximum in USEtox ${ }^{13}$ ). For 374 the metals $\mathrm{Cd}, \mathrm{Co}, \mathrm{Cr}, \mathrm{Mn}, \mathrm{Ni}$ and $\mathrm{Zn}, \mathrm{BF}$ in freshwater and seawater are rather similar. $\mathrm{Cd}, \mathrm{Co}$, $375 \mathrm{Mn}, \mathrm{Ni}$, and $\mathrm{Zn}$ were insensitive to variations in water chemistry in freshwater ${ }^{13}$. Thus it may be 376 reasonable to expect similar BF in freshwater and seawater for these metals. BF of $\mathrm{Cr}$ is correlated 
to $\log \mathrm{K}_{\mathrm{DOC}}$ and $\log \mathrm{Kp}$ Ss. These two values are negatively correlated with both SPM and salinity in

378 estuaries $^{49}$. From the freshwater end to seawater end, salinity increases and SPM decreases, which 379 in combination leads to similar ranges of $\log \mathrm{K}_{\mathrm{DOC}}$ and $\log \mathrm{K} \mathrm{p}_{\mathrm{sS}}$, and thus similar $\mathrm{BF}$ ranges in 380 seawater and freshwater for Cr. In summary, a combination of similar BF in sea- and freshwater, 381 lower EF in seawater, and higher FF in seawater results in a similar range of CTP in seawater and 382 freshwater for $\mathrm{Cd}, \mathrm{Co}, \mathrm{Cr}, \mathrm{Mn}, \mathrm{Ni}$, and $\mathrm{Zn}$ (Figure S9 in SI).

$383 \mathrm{Cu}$ has up to two orders of magnitude higher FF in freshwater. It has a similar BF in freshwater 384 and seawater, for similar reasons as Cr. But its EF is 2-4 orders of magnitude lower in seawater, 385 which results in a slightly lower CTP in seawater (Figure S9 in SI).

$386 \mathrm{~Pb}$ has a FF up to three orders of magnitude higher and a slightly lower EF in seawater than in 387 freshwater. At the same time its BF is 1-2 orders of magnitude higher in seawater, possibly due to 388 lower SPM and OM concentrations in seawater. This results in 1-4 orders of magnitude higher CTP 389 in coastal seawater than in freshwater (Figure S9 in SI).

390 CTP is expressed in potentially affected fraction of species integrated over time and space. 391 However, the species density varies considerably depending on location - from $7 \times 10^{-12}$ to $5 \times 10^{-4}$ 392 species $/ \mathrm{m}^{3}$ in different freshwater ecosystems at various locations ${ }^{67}$. Thus, even if two different 393 archetypes have the same CTP, the number of affected species can in extreme cases differ up to 394 eight orders of magnitude in freshwater. Variation would also be expected for species density in 395 coastal marine ecosystems. Moreover, species density in freshwater is generally about three orders 396 of magnitude higher than in seawater ${ }^{68}$, which should be taken into account when comparing CTP 397 values in freshwater and seawater.

\subsubsection{Comparison of Fate Factors and Bioavailability Factors from USEtox}

399 The current version of USEtox does not provide marine CTP and only has seawater as a fate 400 compartment supporting FF and the eco-exposure factor (XF) calculation for seven of the metals 
401 covered in this study $(\mathrm{Cd}, \mathrm{Co}, \mathrm{Cr}, \mathrm{Cu}, \mathrm{Ni}, \mathrm{Pb}$ and $\mathrm{Zn})$. USEtox operates with a default SRT of one 402 year, which is at the middle range of SRTs applied for the LMEs in this study. The default USEtox 403 FF thus falls within the range of the new FF in this study for all the metals (Figure S9 in SI). BF in 404 this study is similar to the concept of eco-exposure factor (XF) in USEtox. The default XF in 405 USEtox falls within or close to the range of BF found in this study for most metals. The only 406 exceptions are $\mathrm{Cr}$ and $\mathrm{Cu}$, for which the USEtox XF is 1-6 orders of magnitude higher (Figure S9 in $407 \mathrm{SI})$. This is because the default $\mathrm{K}_{\mathrm{DOC}}$ and $\mathrm{K} \mathrm{p}_{\mathrm{SS}}$ values in USEtox were taken from literature ${ }^{69}$, where 408 it was defined as the ratio between absorbed metal and total dissolved metal. Recall that $\mathrm{K}_{\mathrm{DOC}}$ and $409 \mathrm{Kp}_{\mathrm{SS}}$ calculated in this study represent the ratios between absorbed metal and truly dissolved metal. 410 This results in a lower $\mathrm{K}_{\mathrm{DOC}}$ and $\mathrm{Kp}_{\mathrm{SS}}$ in USEtox, which leads to a higher XF.

\section{$411 \quad 3.4 .5 \quad$ Sensitivity analysis}

412 Several water chemistry parameters (DOC, POC, SPM, pH, salinity, metal background 413 concentration and concentrations of Fe oxides, Mn oxides and Al oxides) and environmental 414 parameters (SRT, surface area, freshwater inflow and temperature) are involved in the calculation 415 of CTP in this study. In the following section, we will test the sensitivity of CTP to these 416 parameters.

417 Salinity and $\mathrm{pH}$ values were extracted from a complete datasets ${ }^{70}$. Surface area and freshwater 418 inflow were measured data taken from a global database ${ }^{71}$. They are well established values and 419 their uncertainty are only caused by measurement error. Thus the uncertainty is hence judged to be 420 low (e.g. uncertainty of $\mathrm{pH}$ meter measurement accuracy $<0.1^{72}$, salinity probe $<3 \%{ }^{73}$ ).

421 LME-specific land surface areas were applied in USEtox to calculate CTPs for metals in this 422 study. Compared to the CTPs calculated by applying default land surface area in USEtox, the 423 differences are less than $2 \%$, caused by slightly different air deposition (which is also proportional 424 to the land area). 
The importance of the uncertainty accompanying the $\mathrm{Fe}, \mathrm{Mn}$ and $\mathrm{Al}$ oxide concentrations was tested by changing them by a factor of 10 . As a result CTPs varied less than $10 \%$ for all metals except $\mathrm{Pb}$, for which the variation amounted to $1-35 \%$ across all LMEs. show a significant positive correlation in natural waters (Figure S10 in SI). The parameter values 431 from fresh to marine waters. We therefore tested the sensitivity of CTP to these three parameters, by 432 varying them all together by a factor of $0.1-10$. These variations can cover DOC, POC, and SPM concentrations ranging from conditions in freshwater to the open ocean. For these variations, CTP 434 of $\mathrm{Cr}$ and $\mathrm{Cu}$ show the highest sensitivity, varying between a factor of 0.004 and 168 . The other 435 metals show very modest sensitivity, varying between a factor of 0.2 and 2.2 (Figure S11 in SI). 436 This indicates that CTP is sensitive to DOC, POC and SPM concentrations for $\mathrm{Cr}$ and $\mathrm{Cu}$, but less 437 sensitive for the other metals. Note that within each LME, DOC, POC and SPM vary across 438 locations and time. The average value of these parameters in a specific LME was applied in our 439 study to calculate the corresponding CTP in that LME. Considering the large water volume and 440 surface area in each LME, and the comparatively constant $\mathrm{pH}$, salinity and POC values (Figure S2 441 in SI), the average value of DOC, POC and SPM, thus CTPs are not likely to change dramatically 442 within one LME. However, the uncertainty associated with CTPs of $\mathrm{Cr}$ and $\mathrm{Cu}$ is still comparably 443 larger than the other metals. This needs to be noted when comparing CTPs across metals.

444 SRT has a strong influence on FF for all metals and hence also on the CTP. We varied SRT by 445 two orders of magnitude (0.1X-10X of original values) resulting in a variation in CTP by a factor of $4460.05-21$ (Figure S12 in SI). The variations of CTP and SRT show a similar trend, indicating that 447 CTP positively covariates with SRT. Therefore, SRT is an important parameter determining CTP 
448 when comparing metal CTP across LMEs, but it is less relevant for comparing CTP across metals 449 within the same LME.

450 Temperature has influence on metal speciation, thus potentially influencing FF, BF, and EF. We 451 calculated CTP by changing temperatures to $10^{\circ} \mathrm{C}$ lower or $10^{\circ} \mathrm{C}$ higher than the original values. 452 This variation range covers the surface seawater temperature for the whole year, judging from data 453 in the MODIS database ${ }^{74}$. We found that CTP only varies within a factor of $0.4-2.8$ (Figure S13 in 454 SI) for all metals. For Cr, BF and EF vary up to one order of magnitude. However, BF and EF have 455 positive and negative correlation respectively with temperature and hence partly compensate each 456 other, which results in a moderate change of CTP. It can be concluded here that CTP is not very 457 sensitive to temperatures.

$458 \mathrm{BF}, \mathrm{Kp} \mathrm{SS}_{\text {, and }} \mathrm{K}_{\mathrm{DOC}}$ were calculated from metal background concentration in generic seawater, 459 which may differ in different locations. Therefore we tested the dependence of BF, $\mathrm{Kp}$ SS, and $\mathrm{K}_{\mathrm{DOC}}$ 460 on metal background concentration, by varying background concentration by a factor of $10(0.1 \mathrm{X}-$ 461 10X of original value). For the metals with higher Kpss and $\mathrm{Kdoc}$ values (e.g., $\mathrm{Cr}, \mathrm{Cu}$ and $\mathrm{Fe}$ ), $\mathrm{BF}$ 462 can vary up to one order of magnitude and $\mathrm{K} \mathrm{p}_{\mathrm{SS}}$, and $\mathrm{K}_{\mathrm{DOC}}$ can vary up to two orders of magnitude. 463 The variation is largely caused by metal binding with OMs. For the other metals, the variations of $464 \mathrm{BF}, \mathrm{Kp}$ Ss, and $\mathrm{K}_{\mathrm{DOC}}$ are less than $2 \mathrm{X}$. This result is similar to the observation in Gandhi et al. ${ }^{21}$. It 465 shows that in the systems with higher background concentrations, BFs thus CTPs of metals with 466 higher $\mathrm{Kp} \mathrm{SS}_{\mathrm{S}}$, and $\mathrm{K}_{\mathrm{DOC}}$ values may be underestimated. However, this might be offset by the 467 adaptation of aquatic biota in those systems, which is not considered in the current effect 468 modelling $^{21}$.

\subsection{Practical implications}

470 This study is the first attempt to derive marine CTP considering speciation, bioavailability, 471 seawater specific toxicity, and spatial differentiation. The results show that CTP for one metal can 
vary 3-4 orders of magnitude across LMEs, except for Fe, for which CTP is zero due to its low background concentration and essentiality to marine biota. It was clearly demonstrated that it is of great importance to apply spatially differentiated CTP for metals in coastal seawater, as shown for all metals covered by this study except Fe. This raises the requirement for LCA practitioners to consider the emission location in the inventory. The variation of CTPs is primarily driven by SRT for most metals except $\mathrm{Cr}$ and $\mathrm{Cu}$. If there is any updates on SRT in future research, it is strongly recommended to recalculate metal CTPs correspondingly. Due to limited ecotoxicity data for marine species and the metal coverage of the speciation model WHAM VII, it is difficult to derive marine CTP for additional metals at this point. It is recommended to look into methods to estimate marine ecotoxicity data by extrapolation from freshwater ecotoxicity data, or from known metal properties. This can potentially provide ecotoxicity data for more metals and thus allow calculation 483 of additional marine CTPs. Where measured chronic data was missing, acute toxicity data was extrapolated to chronic $\mathrm{EC}_{50} \mathrm{~s}$ for the $\mathrm{EF}$ calculation of some metals (e.g. $\mathrm{Co}, \mathrm{Cr}, \mathrm{Mn}, \mathrm{Ni}, \mathrm{Pb}$ and $\mathrm{Zn}$, Table S5 in SI). It is recommended to revise these data when chronic data is available. The speciation model WHAM VII cannot simulate metal redox reactions and precipitation except Al and Fe hydroxide. Due to the fact that the CTP developed in this study is for metal in coastal seawater where water column depth is modest and presence of oxides are limited, the occurrence of extreme redox conditions will be rare in most LMEs. E.g., When $\mathrm{Cr}(\mathrm{III})$ is emitted to coastal seawater, its oxidation to $\mathrm{Cr}(\mathrm{IV})$ is limited and slow, unless abundant Mn dioxide and hydroxides 491 exist $^{75}$. However, the lack of precipitation modelling in WHAM can cause some uncertainties, 492 especially for metals which may form insoluble compounds with major anions in seawater. 493 Therefore, it is recommended to explore the possibility of applying other metal speciation models to complement WHAM VII (e.g. MINEQL $+^{38}$, Visual Minteq ${ }^{37}$, CHEAQS Pro $^{76}$ or PHREEQC $^{39}$ ) covering other metals and supporting the modelling of precipitation and redox reactions where 
needed. Literature reported that eutrophication can increase metal bioavailability up to an order of

497 magnitude ${ }^{77,78}$. However, this may be offset by decreasing EF due to organism adaptation, which is 498 not considered in this study. Comparing to 3-4 orders of magnitude variation in CTPs, the 499 uncertainty introduced by differences in eutrophication across LMEs will not have significant 500 influences on the result. FIAM was used to assess EF in this study. However, unlike BLM it does 501 not include competition between free metal ion and other cations for binding to biotic ligands. Thus 502 it is recommended to estimate EFs with marine BLM when available. This study only developed 503 CTP for metals in the water column of the seawater compartment. Ecotoxicity potentials in 504 sediments were not considered here. In LCIA this is typically considered as a separate compartment 505 (if at all) and would require a separate study.

\section{Supporting Information}

5099 tables and 13 figures addressing additional data were presented in supporting information. This 510 material is available free of charge via the internet at http://pubs.acs.org.

\section{AUTHOR INFORMATION}

512 Corresponding Author

513 *Email: yado@dtu.dk. Phone: +45 45254417

\section{Funding Sources}

515 This research is financially supported by the EU commission within the Seventh Framework 516 Programme Environment ENV. 2008.3.3.2.1: PROSUITE - Development and application of a 
517 standardized methodology for the PROspective SUstaInability assessment of Technologies (Grant 518 agreement No.: 227078).

\section{ACKNOWLEDGMENTS}

520 The authors thank Dennis Hansell (RSMAS/MAC, University of Miami) and Reiner Schlitzer 521 (AWI, Helmholtz center for polar and marine research) for providing DOC data. Dr. Rosenbaum 522 gratefully acknowledges the financial support of the partners in the Industrial Chair for Life Cycle 523 Sustainability Assessment ELSA-PACT (a research project of ELSA - Environmental Life Cycle \& 524 Sustainability Assessment): Suez Environment, Société du Canal de Provence (SCP), Compagnie 525 d'aménagement du Bas-Rhône et du Languedoc (BRL), Val d'Orbieu - UCCOAR, EVEA, ANR, 526 IRSTEA, Montpellier SupAgro, École des Mines d'Alès, CIRAD, ONEMA, ADEME, and the 527 Region Languedoc - Roussillon. 


\section{References}

(1) EC-JRC. International Reference Life Cycle Data System (ILCD) Handbook - General guide for Life Cycle Assessment - Detailed guidance; first edit.; Publications Office of the European Union: Luxembourg, LU, 2010.

(2) Hellweg, S.; Milà i Canals, L. Emerging approaches, challenges and opportunities in life cycle assessment. Science (80-. ). 2014, 344, 1109-1113.

(3) Huijbregts, M. A. J.; Thissen, U.; Guinée, J. B.; Jager, T.; Kalf, D.; van de Meent, D.; Ragas, A. M. J.; Wegener Sleeswijk, A.; Reijnders, L. Priority assessment of toxic substances in life cycle assessment. Part I: Calculation of toxicity potentials for 181 substances with the nested multi-media fate, exposure and effects model USES-LCA. Chemosphere 2000, 41, 541-573.

(4) Pacyna, J. M.; Scholtz, M. T.; (Arthur) Li, Y.-F. Global budget of trace metal sources. Environ. Rev. 1995, 3, 145-159.

(5) The European Pollutant Release and Transfer Register. European industrail annual pollutant release; European Environment Agency (EEA): Copenhagen, Denmark, 2012.

(6) Chester, R.; Jickells, T. The transport of material to the oceans: the fluvial pathway. In Marine Geochemistry; Blackwell Publishing Ltd., 2012; pp. 11-51.

(7) Van Zelm, R.; Huijbregts, M. A. J.; van de Meent, D. USES-LCA 2.0-a global nested multi-media fate, exposure, and effects model. Int. J. Life Cycle Assess. 2009, 14, $282-$ 284.

(8) Jolliet, O.; Margni, M.; Charles, R.; Humbert, S.; Payet, J.; Rebitzer, G.; Rosenbaum, R. IMPACT 2002+: a new life cycle impact assessment methodology. Int. J. Life Cycle Assess. 2003, 8, 324-330.

(9) Aboussouan, L.; Saft, R. J.; Schonnenbeck, M.; Hauschild, M. Z.; Delbeke, K.; Struijs, J.; Russell, A.; de Haes, H. U.; Atherton, J.; van Tilborg, W.; et al. Declaration of Apeldoorn on LCIA of non-ferro metals. Results of a workshop by a group of LCA specialists, held in Apeldoorn, NL. SETAC Globe 2004, 5, 46-47.

(10) Diamond, M. L.; Gandhi, N.; Adams, W. J.; Atherton, J.; Bhavsar, S. P.; Bulle, C.; Campbell, P. G. C.; Dubreuil, A.; Fairbrother, A.; Farley, K.; et al. The clearwater consensus: the estimation of metal hazard in fresh water. Int. J. Life Cycle Assess. 2010, $15,143-147$.

(11) Gandhi, N.; Diamond, M. L.; van de Meent, D.; Huijbregts, M. A. J.; Peijnenburg, W. J. G. M.; Guinee, J. New method for calculating Comparative Toxicity Potential of cationic 
metals in freshwater: application to copper, nickel, and zinc. Environ. Sci. Technol. 2010, $44,5195-5201$.

(12) Gandhi, N.; Diamond, M. L.; Huijbregts, M. A. J.; Guinée, J. B.; Peijnenburg, W. J. G. M.; van de Meent, D. Implications of considering metal bioavailability in estimates of freshwater ecotoxicity: examination of two case studies. Int. J. Life Cycle Assess. 2011, 16, 774-787.

(13) Dong, Y.; Gandhi, N.; Hauschild, M. Z. Development of Comparative Toxicity Potentials of 14 cationic metals in freshwater. Chemosphere 2014, 112, 26-33.

(14) Bruland, K.; Lohan, M. Controls on trace metals in seawater. In The Oceans and Marine Geochemistry, Volume 6 of Treatise on geochemistry; Holland, H. D.; Turekian, K. K., Eds.; Elsevier: Amsterdam, 2004; pp. 23-47.

(15) Fu, F.; Wang, Q. Removal of heavy metal ions from wastewaters: a review. J. Environ. Manage. 2011, 92, 407-418.

(16) Paquin, P. R.; Gorsuch, J. W.; Apte, S.; Batley, G. E.; Bowles, K. C.; Campbell, P. G. C.; Delos, C. G.; Di Toro, D. M.; Dwyer, R. L.; Galvez, F.; et al. The biotic ligand model: a historical overview. Comp. Biochem. Physiol. Part C Toxicol. Pharmacol. 2002, 133, 335 .

(17) Sunda, W. Trace metal interactions with marine phytoplankton. Biol. Oceanogr. 1989, 6, 411-442.

(18) Mason, R. P. Trace metal(loid)s in marine waters. In Trace Metals in Aquatic Systems; Blackwell Publishing Ltd, 2013; pp. 219-309.

(19) Rosenbaum, R. K.; Bachmann, T. M.; Gold, L. S.; Huijbregts, M. A. J.; Jolliet, O.; Juraske, R.; Koehler, A.; Larsen, H. F.; MacLeod, M.; Margni, M.; et al. USEtox-the UNEPSETAC toxicity model: recommended characterisation factors for human toxicity and freshwater ecotoxicity in life cycle impact assessment. Int. J. Life Cycle Assess. 2008, 13, 532-546.

(20) Leung, K. M. Y.; Morritt, D.; Wheeler, J. R.; Whitehouse, P.; Sorokin, N.; Toy, R.; Holt, M.; Crane, M. Can saltwater toxicity be predicted from freshwater data? Mar. Pollut. Bull. 2001, 42, 1007-1013.

(21) Gandhi, N.; Huijbregts, M. A. J.; van de Meent, D.; Peijnenburg, W. J. G. M.; Guinee, J.; Diamond, M. L. Implications of geographic variability on Comparative Toxicity Potentials of $\mathrm{Cu}, \mathrm{Ni}$ and $\mathrm{Zn}$ in freshwaters of Canadian ecoregions. Chemosphere 2011, 82, 268-277.

(22) Tankere, S. P. C.; Price, N. B.; Statham, P. J. Mass balance of trace metals in the Adriatic Sea. J. Mar. Syst. 2000, 25, 269-286. 
(23) Brodie, J.; Wolanski, E.; Lewis, S.; Bainbridge, Z. An assessment of residence times of land-sourced contaminants in the Great Barrier Reef lagoon and the implications for management and reef recovery. Mar. Pollut. Bull. 2012, 65, 267-279.

USEPA. ECOTOX database; http://cfpub.epa.gov/ecotox/.

(25) Rosenbaum, R. K.; Margni, M.; Jolliet, O. A flexible matrix algebra framework for the multimedia multipathway modeling of emission to impacts. Environ. Int. 2007, 33, 624634.

(26) Cosme, N.; Larsen, H. F.; Hauschild, M. Z. Chapter 3- Spatially-explicit characterisation factors for marine eutrophication. In Recommended assessment framework, method and characterisation and normalisation factors for ecosystem impacts of eutrophying emissions: phase 3 (report, model and factors). LC-IMPACT deliverable report D3.7 (T3.1: Aquatic eutrophication); Azevedo, L. B.; Cosme, N.; Hauschild, M. Z.; Henderson, A. D.; Huijbregts, M. A. J.; Jolliet, O.; Larsen, H. F.; van Zelm, R., Eds.; Kgs. Lyngby, Denmark, 2013; pp. 58-154.

(27) Chen, C.-T. A.; Liu, K.-K.; Macdonald, R. Continental margin exchanges. In Ocean Biogeochemistry; Fasham, M. R., Ed.; Springer Berlin Heidelberg, 2003; pp. 53-97.

(28) Sherman, K. The Large Marine Ecosystem concept: research and management strategy for living marine resources. Ecol. Appl. 1991, 1, 349-360.

(29) Brown, E.; Colling, A.; Park, D.; Phillips, J.; Rothery, D.; Wright, J. Seawater: its composition, properties and behaviour; Bearman, G., Ed.; 2nd editio.; The Open University, 1995.

(30) Coston, J. A.; Fuller, C. C.; Davis, J. A. Pb2+ and Zn2+ adsorption by a natural aluminum - and iron-bearing surface coating on an aquifer sand. Geochim. Cosmochim. Acta 1995, $59,3535-3547$.

(31) Agrawal, A.; Sahu, K. K. Kinetic and isotherm studies of cadmium adsorption on manganese nodule residue. J. Hazard. Mater. 2006, B137, 915-924.

(32) Phuengprasop, T.; Sittiwong, J.; Unob, F. Removal of heavy metal ions by iron oxide coated sewage sludge. J. Hazard. Mater. 2011, 186, 502-507.

(33) Slemons, L.; Paul, B.; Resing, J.; Murray, J. W. Particulate iron, aluminum, and manganese in the Pacific equatorial undercurrent and low latitude western boundary current sources. Mar. Chem. 2012, 142-144, 54-67.

(34) Hauschild, M. Z.; Huijbregts, M.; Jolliet, O.; MacLeod, M.; Margni, M.; van de Meent, D.; Rosenbaum, R. K.; McKone, T. E. Building a model based on scientific consensus for life cycle impact assessment of chemicals: The search for harmony and parsimony. Environ. Sci. Technol. 2008, 42, 7032-7037. 
(35) Tipping, E.; Lofts, S.; Sonke, J. E. Humic Ion-Binding Model VII: a revised parameterisation of cation-binding by humic substances. Environ. Chem. 2011, 8, 225235.

(36) Stockdale, A.; Tipping, E.; Hamilton-Taylor, J.; Lofts, S. Trace metals in the open oceans: speciation modelling based on humic-type ligands. Environ. Chem. 2011, 8, 304-319.

(37) Gustafsson, J. P. Visual MINTEQ 3.0 user guide; KTH, Department of Land and Water Resources Engineering: Stockholm, Sweden, 2011.

(38) Schecher, W. D.; McAvoy, D. C. MINEQL+ [4.6]: Environmental Research Software; Hallwell, ME, USA, 2003.

(39) Parkhurst, D. L.; Appelo, C. A. J. Description of input and examples for PHREEQC version 3-A computer program for speciation, batch-reaction, one-dimensional transport, and inverse geochemical calculations; U.S. Department of the Interior and U.S. Geological Survey, 2013.

(40) Lorenzo, J. I.; Nieto, O.; Beiras, R. Effect of humic acids on speciation and toxicity of copper to Paracentrotus lividus larvae in seawater. Aquat. Toxicol. 2002, 58, 27-41.

(41) Sunda, W. The relationship between free cupric ion activity and the toxicity of copper to phytoplankton. Ph.D. Dissertation, Massachusetts Institute of Technology and Woods Hole Oceanographic Institution, Cambridge, MA, 1975.

(42) Payet, J. Assessing toxic impacts on aquatic ecosystems in LCA. Ph.D. Dissertation, Ecole Polytechnique Federale de Lausanne: EPFL, CH-1015 Lausanne, 2004.

(43) Henderson, A. D.; Hauschild, M. Z.; van de Meent, D.; Huijbregts, M. A. J.; Larsen, H. F.; Margni, M.; McKone, T. E.; Payet, J.; Rosenbaum, R. K.; Jolliet, O. USEtox fate and ecotoxicity factors for comparative assessment of toxic emissions in life cycle analysis: sensitivity to key chemical properties. Int. J. Life Cycle Assess. 2011, 16, 701-709.

(44) Larsen, H. F.; Hauschild, M. Evaluation of ecotoxicity effect indicators for use in LCIA. Int. J. Life Cycle Assess. 2007, 12, 24-33.

(45) Larsen, H. F.; Hauschild, M. Z. GM-troph: a low data demand ecotoxicity effect indicator for use in LCIA. Int. J. Life Cycle Assess. 2007, 12, 79-91.

(46) Jolliet, O.; Rosenbaum, R.; Chapman, P. M.; McKone, T.; Margni, M.; Scheringer, M.; van Straalen, N.; Wania, F. Establishing a framework for life cycle toxicity assessment findings of the Lausanne review workshop. Int. J. Life Cycle Assess. 2006, 11, 209-212.

(47) Yang, R.; van den Berg, C. M. G. Metal complexation by humic substances in seawater. Environ. Sci. Technol. 2009, 43, 7192-7197. 
(48) Tipping, E. Humic Ion-Binding Model VI: An Improved Description of the Interactions of Protons and Metal Ions with Humic Substances. Aquat. Geochemistry 1998, 4, 3-48.

(49) Turner, A. Trace-metal partitioning in estuaries: importance of salinity and particle concentration. Mar. Chem. 1996, 54, 27-39.

(50) Turner, A.; Martino, M.; Le Roux, S. M. Trace metal distribution coefficients in the Mersey Estuary, UK: evidence for salting out of metal complexes. Environ. Sci. Technol. 2002, 36, 4578-4584.

(51) Li, Y.-H.; Burkhardt, L.; Buchholtz, M.; O’Hara, P.; Santschi, P. H. Partition of radiotracers between suspended particles and seawater. Geochim. Cosmochim. Acta 1984, 48, 2011-2019.

(52) Benoit, M. D.; Kudela, R. M.; Flegal, A. R. Modeled trace element concentrations and partitioning in the San Francisco estuary, based on suspended solids concentration. Environ. Sci. Technol. 2010, 44, 5956-5963.

(53) Baeyens, W.; Parmentier, K.; Goeyens, L.; Ducastel, G.; De Gieter, M.; Leermakers, M. The biogeochemical behaviour of $\mathrm{Cd}, \mathrm{Cu}, \mathrm{Pb}$ and $\mathrm{Zn}$ in the Scheldt estuary: results of the 1995 surveys. Hydrobiologia 1998, 366, 45-62.

(54) Benoit, G.; Cantu, S. D. O.-M.; Hood, E. M.; Coleman, C. H.; Corapcioglu, M. O.; Santschi, P. H. Partitioning of $\mathrm{Cu}, \mathrm{Pb}, \mathrm{Ag}, \mathrm{Zn}, \mathrm{Fe}, \mathrm{Al}$ and $\mathrm{Mn}$ between filter-retained particles, colloids, and solution in six Texas estuaries. Mar. Chem. 1994, 45, 307-336.

(55) Deleersnijder, E.; Campin, J.; Delhez, E. J. M. The concept of age in marine modelling I. Theory and preliminary model results. J. Mar. Syst. 2001, 28, 229-267.

(56) Markus Meier, H. E. Modeling the pathways and ages of inflowing salt- and freshwater in the Baltic Sea. Estuar. Coast. Shelf Sci. 2007, 74, 610-627.

(57) Ivanov, L. M.; Margolina, T. M.; Danilov, A. I. Application of inverse technique to study radioactive pollution and mixing processes in the Arctic Seas. J. Mar. Syst. 2004, 48, 117131.

(58) Orre, S.; Gao, Y.; Drange, H.; Nilsen, J. E. Ø. A reassessment of the dispersion properties of 99Tc in the North Sea and the Norwegian Sea. J. Mar. Syst. 2007, 68, 24-38.

(59) Morel, F. M. M.; Milligan, A. J.; Saito, M. A. Marine bioinorganic chemistry: the role of trace metals in the oceanic cycles of major nutrients. In The Oceans and Marine Geochemistry; Elderfield, H.; Holland, H. D.; Turekian, K. K., Eds.; Elsevier, 2006.

(60) Rengel, Z. Heavy metal as essential nutrients. In Heavy Metal Stress in Plants: From Molecules to Ecosystems; Prasad, M.; Hagemeyer, J., Eds.; Springer-Verlag Berlin Heidelberg: New York, U.S.A., 1999. 
(61) Martin, J. H. Iron as a limiting factor in oceanic productivity. In Primary Productivity and Biogeochemical Cycles in the Sea; Falkowski, P. G.; Woodhead, A. D., Eds.; Environmental Science Research; Springer US, 1992; Vol. 43, pp. 123-137.

(62) Sato, G.; Negassi, S.; Tahiri, A. Z. The only elements required by plants that are deficient in seawater are nitrogen, phosphorous and iron. Cytotechnology 2011, 63, 201-204.

(63) Barsanti, L.; Gualtieri, P. Algae: Anatomy, Biochemicstry, and Biotechnology; 2nd editio.; CSC Press, 2014.

(64) Millero, F. J.; Woosley, R.; Ditrolio, B.; Waters, J. Effect of ocean acidification on the speciation of metals in seawater. Oceanography 2009, 22, 72-85.

(65) Deruytter, D.; Garrevoet, J.; Vandegehuchte, M. B.; Vergucht, E.; Samber, B. De; Vekemans, B.; Appel, K.; Falkenberg, G.; Delbeke, K.; Blust, R.; et al. The combined effect of Dissolved Organic Carbon and salinity on the bioaccumulation of Copper in marine mussel larvae. Environ. Sci. Technol. 2014, 48, 698-705.

(66) Wheeler, J. R.; Leung, K. M. Y.; Morritt, D.; Sorokin, N.; Rogers, H.; Toy, R.; Holt, M.; Whitehouse, P.; Crane, M. Freshwater to saltwater toxicity extrapolation using species sensitivity distributions. Environ. Toxicol. Chem. 2002, 21, 2459-2467.

(67) Azevedo, L. B.; Verones, F.; D, H. A.; van Zelm, R.; Jolliet, O.; Huijbregts, M. A. J. Freshwter eutrophication. In LC-Impact. A spatially differentiated life cycle impact assessment approach; Huijbregts, M. A. J.; Azevedo, L. B.; Chaudhary, A.; Cosme, N.; Fantke, P.; Goedkoop, M.; Hauschild, M.; Hellweg, S.; Laurent, A.; Mutel, C. L.; et al., Eds.; 2014.

(68) Goedkoop, M.; Heijungs, R.; Huijbregts, M.; De Schryver, A.; Struijs, J.; van Zelm, R. ReCiPe 2008: A life cycle impact assessment method which comprises harmonised category indicators at the midpoint and the endoint level; 2013.

(69) Allison, J. D.; Allison, T. L. Partition coefficients for metals in surface water, soil, and waste; U.S. Environmental Protection Agency: Washington, 2005.

(70) National Oceanographic data center (NODC) in United States Department of Commerce. World Ocean Database; http://www.nodc.noaa.gov/OC5/SELECT/dbsearch/dbsearch.html.

(71) Sea Around us. A global database on marine fisheries and ecosystems; www.seaaroundus.org/lme.

(72) HANNA instruments. pH meter by accuracy; http://hannainst.com/usa/subcat.cfm?id=044.

(73) Vernier Software \& Technology. Salinity sensor; http://www.vernier.com/products/sensors/sal-bta/. 
(74) NASA. Moderate Resolution Imaging Spectroradiometer (MODIS); http://aqua.nasa.gov/about/instrument_modis.php.

(75) Sadiq, M. Chapter 6 Chromium in marine environments. In Toxic Metal Chemistry in Marine Environments; CRC Press, 1992.

(76) Verweij, W. CHEAQS Pro, computer program for calculating CHemical Equilibria in AQuatic Systems; http://home.tiscali.nl/cheaqs/.

(77) Li, S.-X.; Liu, F.-J.; Zheng, F.-Y.; Zuo, Y.-G.; Huang, X.-G. Effects of nitrate addition and iron speciation on trace element transfer in coastal food webs under phosphate and iron enrichment. Chemosphere 2013, 91, 1486-1494.

(78) Wang, W.; Dei, R. Effects of major nutrient additions on metal uptake in phytoplankton. Environ. Pollut. 2001, 111, 233-240. 